\title{
Elementos de urbanismo azul: lagos naturales y artificiales
}

\section{Elements of blue urbanism: natural and artificial lakes}

\author{
págs. 22-44
}

Grupo de investigación 1: Territorio y Habitabilidad

Línea de investigación: Arquitectura, Ciudad, Medio Ambiente

Grupo de investigación 2: Bio Tec.

Línea de investigación: Biotecnología con Microalgas

Luis Fernando Molina-Prieto• Diego Rubio Fernández••

\section{RESUMEN}

El artículo aborda un componente clave del urbanismo azul: los lagos urbanos naturales y artificiales. Se estudia la relación de estos cuerpos de agua con el origen de las ciudades, así como su deterioro al ser transformados con el tiempo en vertederos para aguas residuales e industriales. Se analizan: los servicios y beneficios que estos espacios azules aportan a las ciudades y al ambiente; los fenómenos que representan mayores amenazas; y algunos elementos para su restauración o rehabilitación. Se concluye que es labor de los planificadores y diseñadores urbanos rehabilitar o restaurar los lagos urbanos allí donde se encuentren deteriorados, y proponer la construcción de lagos artificiales en las ciudades que carecen de ellos.

Palabras clave: Espacios azules, ecosistemas acuáticos, diseño urbano, ecohidrología.

\begin{abstract}
The article approaches a key component of blue urbanism: urban lakes, whether natural or artificial. It studying the close relationship of these bodies of water with the origin of cities and its deterioration to be transformed over time in landfills of residential and industrial wastewater. It's analysed: the services and benefits that these blue spaces bring to cities and environmental; the phenomena involving higher threats; and some elements for its restoration or rehabilitation. It is concluded that rehabilitate or restore urban lakes wherever they are degraded is a task of urban planners and designers.
\end{abstract}

Key words: Blue spaces, aquatic ecosystems, urban design, ecohydrology.

- Arquitecto, docente investigador Fundación Universidad de América, Imolinaprieto@gmail.com

•• Biólogo, docente investigador Fundación Universidad de América, diego.rubio@investigadores.uamerica.edu.co 
LÍNEA DE INVESTIGACIÓN 1: ARQUITECTURA, CIUDAD, MEDIO AMBIENTE. 2. BIOTECNOLOGÍA CON MICROALGAS

\section{INTRODUCCIÓN}

Desde la antigüedad las ciudades se han localizado cerca de ríos y lagos, de manera que la evolución y la sustentabilidad de la forma urbana han dependido estrechamente de su relación con el agua. La historia del urbanismo da prueba de ello: en torno al río Éufrates -actual Irak- surgió hace 4.700 años Ur de Caldea, considerada por muchos historiadores como la primera ciudad-estado del mundo. En el año 680 a. C., sobre la orilla izquierda del mismo río, fue reconstruida la ciudad de Babilonia por última vez. Siglos después, en el año 52 a. C., las legiones del Imperio Romano fundaban Luteria en el lugar donde cruzar el Sena era más fácil, es decir, en la ile de la Cité, el corazón mismo de París. Los romanos fundaron centenares de ciudades en la cuenca del Mediterráneo y en el norte de Europa, todas ellas en torno a la desembocadura, la confluencia o las márgenes de uno o más ríos. Ejemplo de ello son las fundaciones de Londinium, actual Londres, en las márgenes del Támesis; Barcino, hoy Barcelona, en la desembocadura del Llobregat; Vindobona, actual Viena, a orillas del Danubio; Burdigala, hoy Burdeos, en la desembocadura del Garona; y Lugdunum, hoy Lyon, en la confluencia del Soana y el Ródano, por solo citar unos pocos ejemplos (Cary \& Scullart, 1975; Helal Ouriachen, 2011; Morris, 1984). De igual importancia para el surgimiento y la sostenibilidad de las ciudades han sido los lagos y las lagunas. En Mesoamérica, sobre el lago de Texcoco - hoy sepultado bajo la capital de México—, los aztecas construyeron la ciudad de Tenochtitlan. En Suramérica, en torno a la laguna Rodrigo de Freitas, los colonizadores portugueses levantaron la ciudad de Río de Janeiro. En Norteamérica, en las márgenes del lago Ontario, los colonos ingleses construyeron la fortificación de Fort York, asentamiento que años después se transformaría en la ciudad de Toronto; y en el siglo XIX, en torno al lago Míchigan, se consolidó la ciudad de Chicago (Espinosa-Castillo, 2008; Morris, 1984; Rodrigues, 2012).

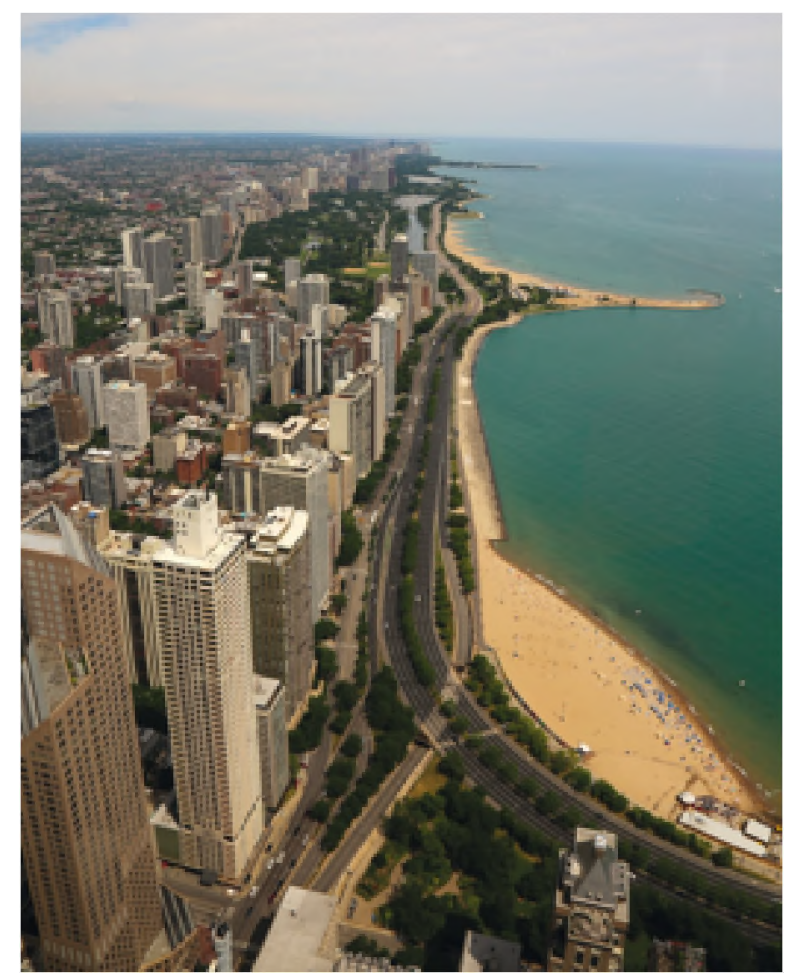

Figura 1. Ciudad de Chicago y lago Míchigan.

Fuente: Cortesía Roberto Pérez Rusi. Docente facultad de Arquitectura, Uamerica. 
Pero gran parte de los ríos y lagos en torno a los cuales surgieron y se consolidaron tantos asentamientos humanos sufrieron, paradójicamente, la rápida degradación de la calidad de sus aguas por efecto de las descargas domésticas e industriales provenientes de las ciudades. A mediados del siglo XIX gran parte de las ciudades industriales habían alterado y degradado física y químicamente los cuerpos de agua que les dieron origen. Gandy (2004) se refiere a la relación agua-ciudad en el período decimonónico como a un caos generalizado gracias al cual se incubó la 'ciudad bacteriológica'. Una urbe insana, insalubre y antihigiénica, que en Europa y América dio origen a numerosas epidemias de cólera, viruela y otras enfermedades contagiosas que cobraron innumerables víctimas. Frente a esta oleada de mortalidad que se inició a principios del siglo XIX y se extendió hasta bien entrado el siglo XX, surgió, desde las ciencias de la salud, el concepto de 'higienismo', y de su mano, la primera legislación sanitaria que fue el "precedente directo de la legislación urbanística" (Benevolo, 1994, p. 122). Los higienistas se enfocaron en los residuos sólidos y líquidos acumulados caóticamente en las ciudades de aquel tiempo, que impactaban de grave manera la salud humana (Lederer \& Kral, 2015). En consecuencia, una de sus más importantes propuestas fue la de conducir las aguas residuales mediante tuberías subterráneas, para que no se mezclaran con las potables ni contaminaran el ambiente urbano. Así surgió el sistema de alcantarillado moderno (Benevolo, 1984).

Si bien el higienismo permitió que las ciudades mejoraran sus condiciones de salubridad, no detuvo las descargas en los cuerpos de agua, ni las redujo, de modo que para las décadas de 1960 y 1970 los ríos, lagos y lagunas — que formaban parte o se hallaban cerca de las ciudades-, se habían convertido en vertederos a cielo abierto de residuos sólidos y líquidos altamente peligrosos, y por ende, sus aguas carecían de vida (Manly \& Owen, 1970; Danielopol, 1976; Williams et al., 1978; Domingos et al., 2012). Esta violenta degradación de la naturaleza, los ecosistemas y la biodiversidad generada por la especie humana, fue una de las muchas razones que dieron pie al movimiento ambientalista, una corriente ideológica que, en cuanto a las aguas urbanas, logró sentar las bases para un cambio de significado y valoración. Gracias al ambientalismo algunos cuerpos de agua urbanos dejaron de ser vertederos domiciliarios e industriales, e iniciaron un lento y prolongado proceso con miras a su restauración, rehabilitación o recuperación; como el río Yarra en Melbourne, Australia, un ecosistema acuático y urbano que hoy se encuentra plenamente saludable (Brown \& Clarke, 2007). No obstante, otros muchos —como el río Bogotá, por ejemplo— están en vísperas de iniciar su propio proceso de descontaminzación, recuperación o restauración.

De otro lado, los sistemas tradicionales de drenaje urbano, o sea, los sumideros superficiales y las tuberías subterráneas cuyo objetivo es extraer las aguas pluviales de las ciudades, han evidenciado en los últimos veinte años su total obsolescencia (Bacchin et al., 2014; Cherrared et al., 2007; Nelson et al., 2007). Lo anterior por dos razones: no dan abasto al rápido incremento demográfico de las ciudades — por su difícil posibilidad de ensanche-; y permiten e incluso fomentan inundaciones urbanas incontrolables como las acontecidas recientemente en ciudades de África (Wade et al., 2009), América (Carvajal-Escobar, 2011; Peterson et al., 2013; Santiago Lastra et al., 2008), Asia (Heikkila \& Huang, 2014; Ranger et al., 2011), Europa (Göransson, 2013; Hilker et al., 2009; Redaud et al., 2002; Thieken et al., 2016) y Oceanía (Wilby \& Keenan, 2012). Otra problemática asociada a los sistemas de drenaje convencionales es que contribuyen a la contaminación de las aguas superficiales y subterráneas de las ciudades, porque recogen las escorrentías pluviales que inevitablemente arrastran consigo tres tipos de contaminantes: residuos de derivados del petróleo, dióxido de carbono y metales pesados (Azizuddin et al., 2014; Calderón et al., 2009; Zhang et al., 2012). 
LÍNEA DE INVESTIGACIÓN 1: ARQUITECTURA, CIUDAD, MEDIO AMBIENTE. 2. BIOTECNOLOGÍA CON MICROALGAS

En la evolución de la forma urbana la relación agua-ciudad ha jugado un papel fundamental. A partir de esa relación estrecha y vital Kaushal et al. (2015) identifican tres grandes pasos en el desenvolvimiento y progreso de las ciudades, todos ellos asociados con el agua: (i) Ciudades industriales, durante el siglo XIX se asentaron cerca de ríos o lagos aprovechando el agua para sus procesos industriales, la navegabilidad de los cauces para el comercio, y la fuerza de los caudales para la generación de energía. Estas ciudades fueron las primeras en contaminar los cuerpos de agua con materiales altamente tóxicos; (ii) Ciudades sanitarias, surgieron para hacer frente a las epidemias generadas por las ciudades industriales. Se caracterizan por la construcción de acueductos y alcantarillados; y (iii) Ciudades sostenibles, que actualmente están configurándose y consolidándose. En algunos casos la sostenibilidad —y la resiliencia- de las ciudades, se está desarrollando a partir del fortalecimiento de los elementos 'azules'1 de la infraestructura verde ${ }^{2}$ (Wagner, 2013), en otros, mediante la vinculación de conceptos netamente 'azules' a los procesos de diseño y planificación urbana. A este respecto se destacan cinco nuevos conceptos creados para independizar y hacer más eficiente la gestión de los cuerpos de agua urbanos: los 'espacios azules' (Nutsford et al., 2016; Raymond et al., 2016), la 'infraestructura azul' (Conrad et al., 2015; Deak \& Bucht, 2011; Von Malotki, 2015), los 'ecosistemas urbanos azules' (Haase, 2015), el 'urbanismo azul' (Beatley, 2014; Jakabfi, 2016) y las 'ciudades azules' (Beatley, 2014).

\section{MÉTODOS}

La investigación contó con tres momentos: (i) obtención de conocimiento sobre el objeto de estudio: revisión bibliográfica enfocada a los lagos urbanos, incluyendo los servicios ambientales que brindan a las ciudades y a los ecosistemas; los fenómenos de origen antrópico que más los afectan y algunos elementos esenciales para su restauración; (ii) elaboración del modelo de procedimiento y método de análisis; y (iii) análisis de la información e interpretación de los resultados.

\section{RESULTADOS}

\section{Lagos urbanos: beneficios}

En las últimas décadas los lagos urbanos han cobrado gran importancia por sus cualidades estéticas que realzan y otorgan sentido a los ambientes urbanos; por ser lugares donde los ciudadanos pueden entrar en contacto con la naturaleza; por ser escenarios óptimos para la recreación y el turismo; por su capacidad para conducir y almacenar agua, regular el clima, fortalecer el ciclo hidrológico, gestionar las aguas pluviales y contribuir con la conservación de la flora y la fauna, entre otras cosas (Chaudhry et al., 2013; Voigt et al., 2014; Völker et al., 2013).

A nivel del paisaje los lagos urbanos aportan a la ciudad dos importantes facetas: por un lado generan espacios abiertos y amplios, opuestos a la congestión y la estrechez características de las zonas urbanizadas, y por otro, permiten la contemplación del agua, en algunos casos acompañada por la

1 Es decir: ríos, quebradas, canales, lagos, lagunas, estanques, humedales, e incluso las áreas costeras.

2 Concepto espacial surgido en la década de 1990 en los Estados Unidos que comprende la red de espacios urbanos verdes, con el fin de planificarlos para aprovechar los servicios ambientales y ecológicos que por naturaleza ellos proporcionan a las ciudades. La Infraestructura Verde incluye tres elementos: las áreas de reserva natural; los parques de cualquier tamaño; y los cuerpos de agua junto con sus rondas hídricas (Remolina, 2011). 


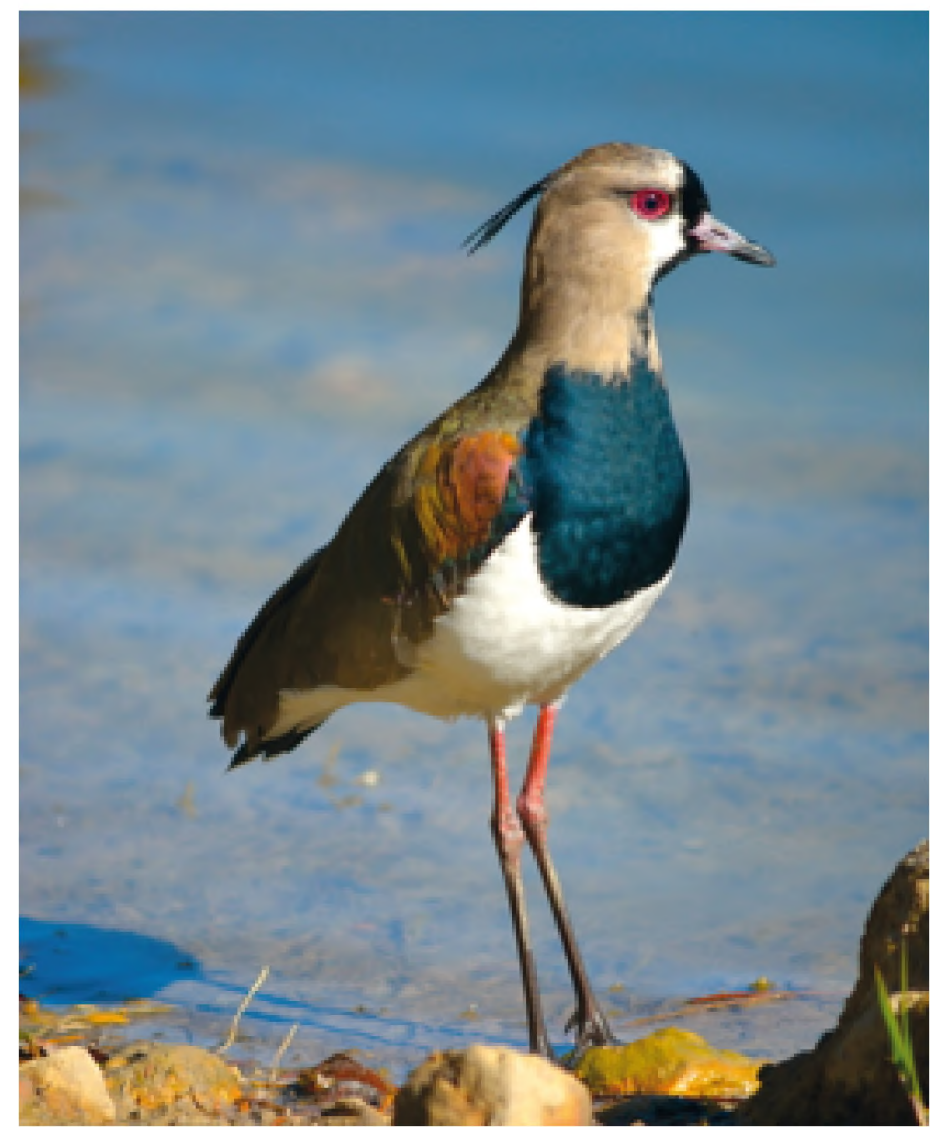

Figura 2. Alcaraván (Vanellus chilensis). Parue El Lago, Bogotá Fuente: Elaboración propia.

presencia significativa y enriquecedora de diversas especies de aves acuáticas (Zhang et al., 2015). Estos atributos tan particulares, que reducen el estrés e incrementan la sensación de tranquilidad a quien los contempla (Nutsford et al., 2016), están siendo considerados materia de investigación por las ciencias médicas. Völker \& Kistemann (2010), por ejemplo, concluyen que la presencia de lagos en las ciudades aporta bienestar físico y mental a la ciudadanía, por crear paisajes terapéuticos que inciden positivamente en la salud pública. Por su parte Foley \& Kistemann (2015) utilizan palabras de la medicina contemporánea al considerar los lagos urbanos, pues según estos investigadores, son fuente de salutogénesis ${ }^{3}$ en las ciudades. Es decir: son lugares -ambientes, entornos, ecosistemas-que contribuyen de manera significativa en los procesos de fortalecimiento y restauración de la salud humana. Enfoque que además evidencian los estudios de Tanaka et al. (1996) y Takano et al. (2002), en los que se destaca la estrecha relación entre, el acceso de la población a los lagos urbanos, y su la salud y longevidad.

En cuanto a la biodiversidad los lagos urbanos contribuyen en gran medida a la conservación de la fauna local, regional y migratoria, puesto que generan parches de hábitat que además de conte-

3 La salutogénesis es un nuevo paradigma de las ciencias médicas que contrasta con la visión tradicional que se enfoca en remediar o dar solución a las patologías. Su etimología proviene de 'salud' y 'génesis', por lo que puede significar: lo que genera salud (Strümpfer, 1990). 
ner especies locales funcionan como lugares de paso que facilitan el movimiento de muchas especies a través del paisaje, especialmente de las aves, puesto que les sirven como lugar de descanso y alimentación durante sus desplazamientos cotidianos, y además, a lo largo de sus migraciones. Gran parte de la biodiversidad que reside en los lagos urbanos - que en ocasiones incluye especies endémicas y en riesgo de extinción-, permanece en ellos a pesar de los vectores de estrés de origen antrópico propios de las ciudades, como son el tráfico automotor, la contaminación del aire o la polución de los cuerpos de agua, bien sea por materia orgánica o por metales pesados (Hassall, 2014; McCleery et al., 2014). Por contribuir de manera eficiente y eficaz en la conservación de la avifauna, actualmente se adelantan planes para la conservación de los particulares ecosistemas que establecen los lagos urbanos (Rajashekara \& Venkatesha, 2014).

Otro importante aporte de los lagos a las ciudades es el económico. A ese respecto Chaudhry et al. (2013) estudiaron el caso del lago Sukhna, en Chandigarh, India. Un cuerpo de agua artificial que hizo parte del plan maestro que, en la década de 1950, propuso para esa ciudad Le Corbusier, el afamado arquitecto del Movimiento Moderno.

El lago Sukhna se formó en 1958 mediante la construcción de una represa de tierra de tres kilómetros de longitud y 14 metros de altura, sobre el Sukhna Choe, un drenaje de aguas pluviales. En la actualidad cuenta con una extensión de 42 kilómetros cuadrados y es alimentado por dos torrentes de montaña: el Kansal y el Nepli Choes. El lago Sukhna es uno de los lugares más importantes para la recreación al aire libre y el turismo en el norte de la India (recibe casi un millón de turistas por año, la mayor parte nacionales, además de un buen porcentaje de extranjeros). Chaundhry et al. destacan la importancia que, para la economía de la ciudad de Chandigarh, representa este lago artificial que actualmente hospeda una amplia variedad de especies de aves acuáticas, por lo que los investigadores consideran pertinete también promocionarlo como destino ecoturístico, otro importante renglón de la economía del siglo XXI.

Los cuatro tipos de servicios ambientales que ofrecen los lagos a las ciudades son: aprovisionamiento, regulación, cultura y apoyo. Los servicios de aprovisionamiento conciernen a la producción de elementos propios de los ecosistemas, como agua, alimentos, energía y recursos genéticos. Los servicios de regulación se refieren a los beneficios que generan los ecosistemas acuáticos sobre las áreas urbanas: regulación del clima, purificación del agua, control de la erosión, y de otro lado, la oportunidad de acceso a la naturaleza por parte de la ciudadanía. Los servicios culturales corresponden a los beneficios no materiales que surgen de los lagos urbanos, es decir: los valores educativos, estéticos y espirituales que proporcionan a los habitantes de las ciudades, y además, la disposición de espacios para actividades lúdicas y recreativas. Por último, los servicios de apoyo son indirectos e incluyen la producción primaria, es decir, la base de todas las cadenas alimentarias, la producción de oxígeno, la formación de suelo, el fortalecimiento del ciclo del agua y la disposición de hábitat para innumerables especies de peces, anfibios y aves (Liu, 2014; Lundy \& Wade, 2011; Völker et al., 2013).

Cabe subrayar que, pese a los enormes beneficios y servicios que los lagos urbanos aportan a las ciudades, al ambiente, al paisaje y a la ciudadanía, su estudio se ha pasado por alto históricamente, de manera que se trata de un campo de conocimiento con poca presencia en la literatura, el cual solo recientemente ha cobrado interés para la comunidad científica (Elías-Fernández et al., 2006; Noble \& Hassall, 2015; Singh et al., 2016) 


\section{Lagos urbanos: amenazas}

Desde la antigüedad los lagos urbanos fueron utilizados para almacenar aguas lluvias, garantizando el suministro a la población, y eran altamente valorados sin importar si eran naturales 0 artificiales, grandes y profundos o relativamente pequeños y poco profundos, porque incrementaban la calidad de vida de los ciudadanos. Esta condición cambió radicalmente en el siglo XX puesto que la mayor parte de estos cuerpos de agua se deterioraron y sus aguas fueron contaminadas por mala gestión por parte de los seres humanos (Naselli-Flores, 2008). Pero ahora que retorna el interés por los lagos urbanos y los múltiples servicios ambientales que ellos generan, es de gran importancia su cuidado y conservación. Para contribuir con ese objetivo, a continuación se presentan algunas de las amenazas que en la actualidad ponen en riesgo la salud de estos importantes elementos del urbanismo azul.

\section{Sedimentación}

En los lagos la capa de sedimento hace parte integral del ecosistema, y por ende, se establece un sinnúmero de interacciones entre el cuerpo de agua y el material sedimentado. En los lagos naturales los sedimentos actúan como depósito y fuente de nutrientes, y la calidad y cantidad de especies de flora y fauna que habitan en el cuerpo de agua y sus márgenes, son factores que inciden directamente en la tasa de sedimentación (Gunkel, 2003). Pero en los lagos urbanos la sedimentación es un proceso que puede acelerarse o ralentizarse por factores antrópicos; y el contenido y las características de los sedimentos pueden presentar grandes cantidades de elementos contaminantes, como por ejemplo: partículas provenientes de la erosión de los materiales adyacentes; residuos industriales, decantación atmosférica, vertimientos provenientes de alcantarillados, entre muchos otros (Galán et al., 2009). Los procesos de urbanización afectan la cobertura vegetal natural y en consecuencia pueden incrementar la erosión del suelo, lo que lleva a una mayor afluencia de sedimentos hacia los lagos, sean o no urbanos. En Virginia, Estados Unidos, Newman et al. (2006) realizaron un estudio en el College Lake, un reservorio artificial construido en 1934 en la ciudad de Lynchburg, que debido al crecimiento urbano de las últimas dos décadas ha acelerado de manera muy significativa sus procesos de sedimentación, al punto de perder la profundidad de sus aguas así como su capacidad de almacenamiento. Según los investigadores, si no se toman medidas a tiempo, College Lake corre alto riesgo de convertirse en un pantano para finalmente desecarse por completo.

Situación a la que se ve abocada una buena parte de los lagos urbanos. En cuanto a la calidad y el contenido de los sedimentos de estos ecosistemas cabe señalar que en muchos casos se encuentran altas concentraciones de coliformes fecales y metales pesados (Almanza-Marroquín et al., 2016), no obstante, una fracción menor pero importante del material sedimentario está conformada por materia orgánica proveniente de fuentes naturales: detritus vegetal de plantas superiores, restos de microorganismos animales, partículas en suspensión arrastradas por la lluvia, y desechos líquidos y sólidos provenientes de sectores urbanizados (Azizuddin et al., 2014). Por último, cabe subrayar que los sedimentos de los lagos urbanos son importantes archivos de información ambiental que pueden actuar como 'geocronómetros' que indican los cambios ambientales históricos y presentan evidencias de todos los materiales, contaminantes o no, que a lo largo del tiempo han ingresado a un lago (Guo et al., 2013).

\section{Pérdida de la calidad del agua}

Debido a que los lagos urbanos se encuentran muy expuestos a diversas fuentes contaminantes, la calidad del agua experimenta, desde cambios moderados hasta severas alteraciones. Para evaluar 
LÍNEA DE INVESTIGACIÓN 1: ARQUITECTURA, CIUDAD, MEDIO AMBIENTE. 2. BIOTECNOLOGÍA CON MICROALGAS

la calidad del agua en dos lagos urbanos de la ciudad de Mumbay, India, Ratheesh Kumar et al. (2015) utilizaron el método estándar de la American Public Health Association (APHA, 2005), el cual incluye un total de 22 parámetros físico-químicos: profundidad del agua, temperatura del agua, transparencia, $\mathrm{pH}$, conductividad eléctrica, oxígeno disuelto (OD), demanda bioquímica de oxígeno, alcalinidad total, fósforo reactivo, nitrato-nitrógeno, amoníaco-nitrógeno, carbono orgánico total, sodio, potasio, calcio y metales pesados tales como cobre, cromo, níquel, hierro, magnesio y plomo. Además, tomaron muestras del fitoplancton, puesto que por ser el productor primario en los ecosistemas acuáticos, revela datos muy importantes sobre la salud y la calidad de los cuerpos de agua. En cuanto a la contaminación orgánica consideraron los cinco índices propuestos por Nygaard, a partir de los cuales se puede valorar la situación trófica de un lago particular, lo que incluye la presencia de las algas planctónicas que se desarrollan en medios acuáticos contaminados, siendo considerados tales grupos de algas como contaminación orgánica. A ese respecto también tuvieron en cuenta el índice de Palmer, bajo el cual los cuerpos de agua se clasifican como oligotróficos, ${ }^{4}$ mesotróficos ${ }^{5}$ o eutróficos. ${ }^{6}$ También en la India, Tailor \& Mankodi (2013) estudiaron la calidad del agua en dos lagos de la ciudad de Vodadora, uno natural y el otro artificial. Ellos tuvieron en cuenta únicamente seis parámetros químicos: oxígeno disuelto, $\mathrm{pH}$, cloruro, dureza total ${ }^{7}$, fosfatos y nitratos.

En la Ciudad de México Elías-Fernández et al. (2006) realizaron estudios en el lago urbano del Parque Tezozomoc. Para valorar la calidad del agua analizaron siete variables físico-químicas: transparencia, alcalinidad, dureza, $\mathrm{pH}$, conductividad, temperatura y turbiedad. Por su parte, Effler \& Matthews (2008) consideran que el oxígeno disuelto (OD) es un recurso fundamental de los lagos, porque tiene efectos profundos en la biología y la química de esos ecosistemas, y por tanto, lo consideran el indicador más importante de la calidad del agua. De otro lado, Bonansea et al. (2012) consideran que los parámetros bio-físicos comúnmente seleccionados para analizar la calidad del agua en un reservorio acuático son tres: la concentración de clorofila-a, los sedimentos en suspensión y la transparencia del agua.

\section{Escorrentías pluviales contaminadas}

Las escorrentías pluviales urbanas arrastran consigo una serie de sustancias contaminantes que, en muchos casos, son descargadas directamente en los lagos urbanos. Se destacan: (i) residuos de derivados del petróleo que van a parar a los cuerpos de agua, como hidrocarburos (gasolina y diésel), lubricantes (aceites y grasas) y otra serie de aditivos (líquidos para frenos, entre otros) utilizados por el parque automotor; y (ii) material generado por las emisiones vehiculares, especialmente dióxido de carbono y metales pesados como aluminio, azufre, boro, bario, calcio, cadmio, cobalto, cobre, cromo, fósforo, hierro, magnesio, manganeso, níquel, plomo, potasio, sodio y zinc (Azizuddin et al., 2014; Calderón et al., 2009; Zhang et al., 2012).

4 "Oligotrofia. Propiedad de las aguas de lagos profundos de alta montaña, con escasa cantidad de sustancias nutritivas y poca producción de fitoplancton" (RAE en línea).

5 "Mesotrofia. Propiedad de las aguas de lagos con poca transparencia y escasa profundidad, que no son ni oligotróficos ni eutróficos" (RAE en línea).

6 "Eutrofización. Incremento de sustancias nutritivas en aguas dulces de lagos y embalses, que provoca un exceso de fitoplancton" (RAE en línea).

7 "Se entiende por dureza total la suma de las durezas individuales debidas a los iones de calcio, magnesio, estroncio y bario en forma de carbonato o bicarbonato" (www.ambientum.com). 


\section{Descarga de aguas residuales residenciales}

La descarga de aguas residuales residenciales en lagos urbanos, es un fenómeno que afecta tanto a los países en desarrollo como a los desarrollados. En los primeros, por lo general las redes de alcantarillado no abarcan la totalidad de las áreas urbanizadas, obligando a las comunidades que no tienen acceso a este servicio público a verter las aguas servidas generadas por sus viviendas directamente en quebradas, ríos, lagos, lagunas y humedales urbanos, como reportan Ahmed et al. (2010) en la ciudad de Dhaka, la capital de Bangladesh. Esta contaminación incide en los altos índices de mortalidad infantil por enfermedades asociadas al consumo de aguas contaminadas con excretas humanas. De otro lado, en las grandes ciudades de los países desarrollados, es tal la complejidad de la infraestructura de aguas servidas y pluviales, que resulta difícil impedir la contaminación de los grandes cuerpos de agua con contaminación fecal, como evidencian Newton et al. (2013) en el lago Michigan, en la ciudad de Chicago; pero como las aguas de este lago no son utilizadas para el consumo humano, no impactan de manera tan grave a la población urbana.

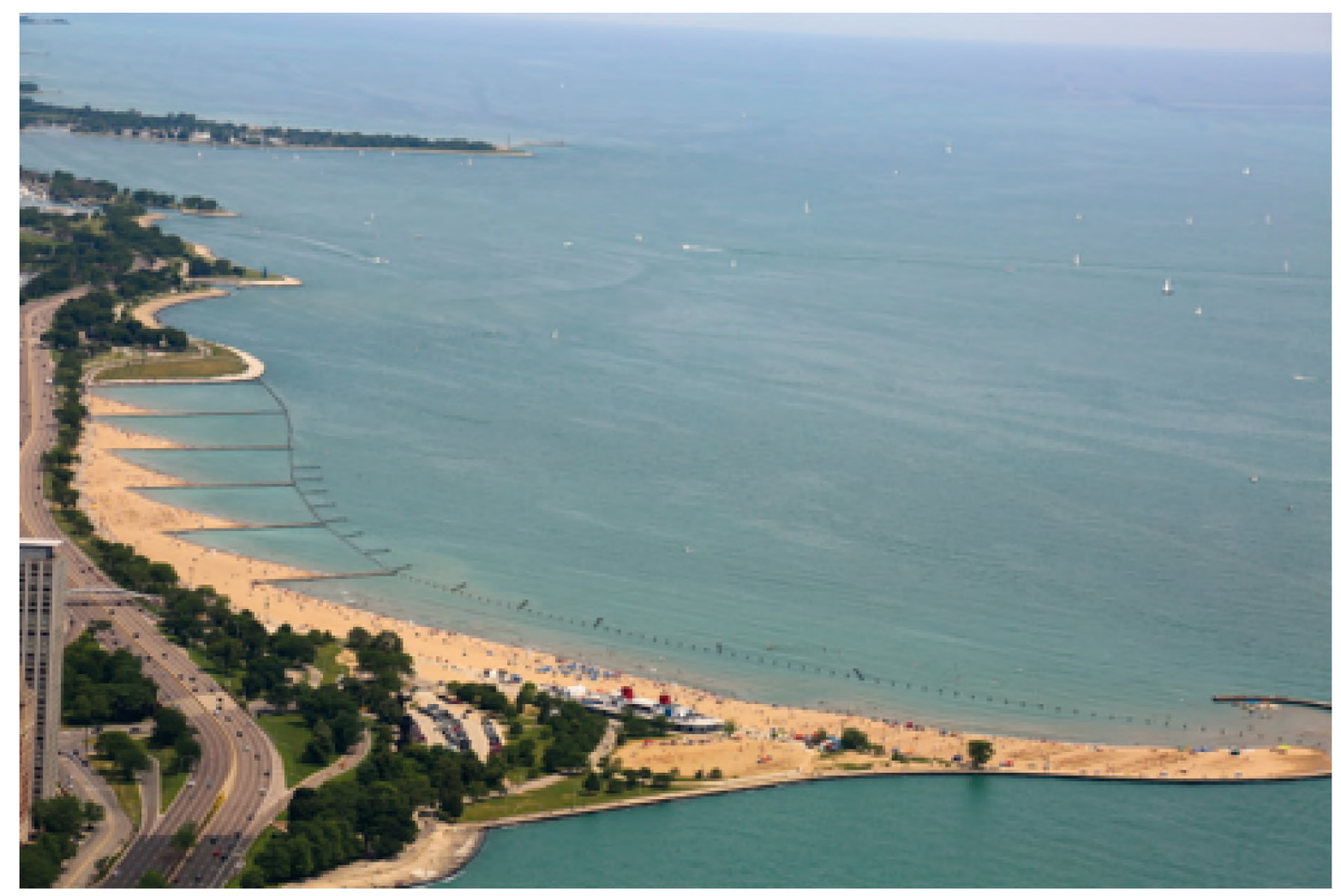

Figura 3. Bahía del Lago Míchigán, frente a Chicago.

Fuente: Cortesía Roberto Pérez Rusi. Docente facultad de Arquitectura, U. América.

\section{Exceso de nutrientes}

Los lagos urbanos usualmente reciben una mayor cantidad de nutrientes que los no-urbanos, en consecuencia, se produce una mayor eutrofización de sus aguas. Esto se debe a que las cuencas urbanas captan una mayor carga de nutrientes por unidad de área que las rurales o naturales (Huser et al., 2016; Malakpour et al., 2016). 
LÍNEA DE INVESTIGACIÓN 1: ARQUITECTURA, CIUDAD, MEDIO AMBIENTE. 2. BIOTECNOLOGÍA CON MICROALGAS

\section{Eutrofización ${ }^{8}$}

El estado trófico de un lago depende de la cantidad de nutrientes que contiene. Como ya se mencionó, ese estado puede ser oligotrófico, mesotrófico o eutrófico. La concentración de nutrientes (especialmente de fósforo) en el agua y los sedimentos de un lago, puede generar la eutrofización o hipereutrofización del mismo. Cuando un lago contiene un exceso de nutrientes no existen limitantes que impidan el desarrollo de la biomasa, y por ende, el desarrollo de la flora no tiene límite. Esto da paso a la proliferación de algunas especies de algas y plantas flotantes, llegando a densificarse de manera tal, que cubren el espejo de agua, enturbian el agua e impiden el ingreso de la radiación solar hasta el fondo del ecosistema. En consecuencia, en el fondo se detienen los procesos de fotosíntesis ${ }^{9}$ y la producción de oxígeno, lo que transforma al ecosistema en un ambiente anóxico (carente de oxígeno) en el que no sobreviven las especies que poblaban el lago cuando no se había eutrofizado (Moreta Pozo, 2008; Rodríguez et al., 1997). Mientras que las entradas excesivas de nitrógeno, patógenos y materia orgánica afectan la calidad del agua de manera natural, las entradas excesivas de fósforo son la causa principal de la eutrofización cultural de los lagos (Huser et al., 2016). Este fenómeno, que en el mayor número de casos se produce por causas antrópicas, define la diversidad y la densidad de las comunidades planctónicas. Por lo general, mientras la eutrofización incrementa la densidad de una especie (comúnmente las algas), se reduce verticalmente la diversidad fitoplanctónica del ecosistema. Esta relación entre densidad y diversidad fue señalada en 1983 por Margalef (Nabout \& Nogueira, 2011).

\section{Afloramiento (Bloom) de cianobacterias}

Las cianobacterias son los organismos fotoautótrofos ${ }^{10}$ más antiguos de la tierra y su capacidad para producir oxígeno ha incidido de manera significativa en la conformación de la biósfera (Paerl \& Otten, 2013). En los lagos y lagunas se presentan principalmente en forma de algas, algunas de las cuales pueden ser altamente tóxicas durante sus picos poblacionales (Quiros, 2004). Bajo ciertas condiciones de temperatura, nutrientes, $\mathrm{pH}$ y otras variables fisicoquímicas, se pueden presentar estos picos poblacionales, lo que genera amenazas para la salud humana dado el potencial de algunos géneros para acumular toxinas a nivel intracelular, que pueden ser liberadas durante los afloramientos, como sucede con el género Mycrocystis, entre otros. Los afloramientos de cianobacterias se producen por la eutrofización y la sedimentación de los cuerpos de agua, por tanto, es esencial controlar las fuentes externas que aceleran estos dos procesos (Kalaji et al., 2016; Waajen et al., 2014). Las cianobacterias filamentosas que se encuentran en muchos lagos urbanos pueden ser tóxicas tanto para los organismos acuáticos como para los seres humanos. Pineda-Mendoza et al. (2012) estudiaron 17 cepas de cianobacterias filamentosas en tres diferentes lagos urbanos en la Ciudad de México: uno en el Parque Ecológico de Chapultepec; el segundo en el Parque Ecológico Alameda de Oriente; y el tercero en la Pista Olímpica de Remo y Canotaje 'Virgilio Uribe' en Cuemanco; y concluyeron que las microcistinas ${ }^{11}$ (MCs) son las principales toxinas sintetizadas por

8 "Eutrofización es el enriquecimiento de las aguas superficiales con nutrientes disponibles para las plantas. Si bien la eutrofización se produce en forma natural, normalmente está asociada a fuentes antropogénicas de nutrientes. El 'estado trófico' de los lagos es un concepto fundamental en la gestión de los mismos" (Moreno Franco et al., 2010, pag. 25).

9 "La fotosíntesis es el proceso por el cual las plantas, algas, cianobacterias y bacterias fotosintéticas convierten la energía luminosa en energía química en forma de enlaces químicos y es la base de todas las cadenas alimenticias de las que depende la vida animal y humana" (González Moreno et al., 2008, pag. 119).

10 Organismos capaces de realizar procesos de fotosintesis para producir energía.

11 "Las Microcistinas (MCs) son toxinas peptídicas de bajo peso molecular, producidas por diferentes especies de algas cianofíceas (blue-green algae), fundamentalmente de los géneros Mycrocystis, Anabaena, Oscillatoria, y Nostoc que crecen a veces de forma anormal en aguas superficiales originando intoxicaciones tanto en animales como en humanos, a veces 
las cianobacterias, las cuales afectan al zooplancton filtrador, como los cladóceros ${ }^{12}$. Por su parte, Arzate-Cárdenas et al. (2010), advierten sobre los posibles riesgos tóxicos que los afloramientos de cianobacterias pueden tener sobre la biota acuática, las personas que visitan estos ecosistemas y las áreas vecinas a los lagos urbanos donde se presenta ese fenómeno.

\section{Concentración de clorofila-a}

En términos generales, la clorofila es un pigmento que permite la fijación fotosintética del carbono en longitudes de onda entre los 400 y 700 nanómetros ${ }^{13}$ en otras palabras: dentro del espectro visible. Existen dos tipos: la clorofila-a y la clorofila- $b$, y se diferencian por su estructura molecular. En los vegetales superiores la clorofila-a es la más abundante, y en los ecosistemas acuáticos, hace parte del fitoplancton.

Por formar parte activa de las poblaciones de algas, la clorofila-a permite cuantificar la biomasa conformada por los microorganismos fotosintéticos presentes en un ecosistema (Begon et al., 2006), aspecto que se ha correlacionado, entre otras cosas, con el fósforo total presente en un lago (Spears et al., 2013).

En consecuencia, la concentración de clorofila-a se emplea actualmente en los lagos urbanos como indicador fiable para determinar: (i) la salud o la vulnerabilidad del ecosistema; (ii) la calidad del agua; (iii) la productividad primaria; (iv) el avance en los procesos de eutrofización; y (v) el estado trófico del cuerpo de agua. Dunalska et al. (2015) defininen como lagos oligotróficos a los que presentan una concentración inferior a $2.5 \mu \mathrm{g} \mathrm{P} / \mathrm{dm}^{3}$ de clorofila-a, y lagos hipertróficos a los que tienen concentraciones superiores a $25 \mu \mathrm{g} \mathrm{P} / \mathrm{dm}^{3} .{ }^{14}$ Los niveles elevados de clorofila-a son signo de deterioro en la salud de los ecosistemas acuáticos, y de acuerdo con Pizarro et al. (2016), en los lagos urbanos y en los que están cerca de las áreas urbanas, son frecuentes las altas concentraciones. Con base en la concentración de clorofila-a, Wainger et al. (2016) definieron zonas de calidad del agua en lagos cercanos a Chesapeake Bay, en Estados Unidos; en tanto Vera-Franco et al. (2015), evaluaron el estado trófico de 18 lagos en Chiapas, México. Por su parte, Zeng (2010), estudió el riesgo de afloramiento de algas en diferentes lagos urbanos en Beijing, para lo cual simuló la distribución de la concentración de clorofila-a, es decir, relacionó la concentración de clorofila-a con el potencial de degradación de la calidad del agua en los lagos urbanos que abarcó el estudio. Cabe señalar que Bonansea et al. (2012) consideran que la concentración de clorofila-a está relacionada con la concentración de nutrientes (fósforo total y nitrógeno total), la penetración de la luz y la temperatura del agua.

\section{Daños físicos por urbanizaciones ilegales}

Esta amenaza se presenta únicamente en los países en desarrollo, pues debido al déficit de vivienda y la falta de soluciones adecuadas por parte del Estado, es muy común que los procesos de crecimiento urbano se realicen en un régimen de ilegalidad, donde las autoridades pierden el control

incluso fatales, por lo que están consideradas como un problema ambiental, ecotoxicológico y principalmente sanitario" (Moreno Navarro, 2002, pag. 5).

12 Los cladóceros son crustáceos diminutos que se conocen como pulgas de agua (www.elmarafondo.com).

13 Unidad de longitud que equivale a la mil millonésima parte de un metro.

14 Es importante aclarar que $P$ en las unidades hace referencia al fosforo, dado que la clorofila-a se mide en correlación con el fosforo presente en los cuerpos de agua. 
de los asentamientos y sus particularidades. En Latinoamérica a este fenómeno se le conoce con dos nombres: asentamientos informales y ciudad informal, y su característica es la transgresión en lo concerniente a la normativa urbana. La invasión del espacio urbano afecta significativamente, en países de África, Asia y América Latina, a los lagos (al igual que a los humedales). Las urbanizaciones ilegales invaden las rondas hídricas, y al hacerlo, desecan los cuerpos de agua, y en algunos casos, vierten sus residuos sólidos y líquidos en los cuerpos de agua, contaminándolos, como sucede en Dhaka, Bangladesh (Islam et al., 2012), o Nagpur, en la India (Patil et al., 2015).

\section{Riesgos por cambio climático}

Factores climáticos como la precipitación, la velocidad del viento y la temperatura ambiente, inciden directamente en los vectores que generan la eutrofización de los cuerpos de agua. Los estudios de Wu et al. (2014) realizados en doce lagos de la ciudad de Beijing, China, demuestran que los cambios en la pluviosidad, la temperatura del aire y la velocidad del viento, alteran de manera significativa los siete indicadores físicos, químicos y biológicos causantes de la eutrofización en los cuerpos de agua: fósforo total, nitrógeno total, concentración de clorofila-a, demanda química de oxígeno, demanda biológica de oxígeno, oxígeno disuelto (OD) y temperatura del agua. Los rangos de concentración de clorofila a, por ejemplo, oscilaron entre 3 y $199 \mathrm{mg} / \mathrm{m}^{3}$, y estas variaciones correspondieron con cambios en la precipitación, la velocidad del viento y la cantidad de horas de sol. En consecuencia Wu et al. (2014) concluyen que los lagos urbanos podrían enfrentar grandes eventos de deterioro por eutrofización, debido al cambio climático.

\section{Lagos urbanos: rehabilitación/restauración}

Nagendra \& Ostrom (2014) realizaron un estudio en un conjunto de siete lagos en la ciudad de Bangalore, India, que otrora fue famosa por sus grandes y numerosos cuerpos de agua. Pero como sucedió en otras latitudes, muchos de estos lagos sufrieron grandes afectaciones físicas por invasiones ilegales, otros fueron desecados, y muchos perdieron la calidad de sus aguas por efecto de la contaminación. Además, los procesos de urbanización deterioraron la percepción de la población sobre estos espacios azules y su administración cayó en manos de una serie de departamentos gubernamentales con múltiples jurisdicciones superpuestas, que dieron paso a su degradación. Los procesos de rehabilitación y restauración de los lagos de Bangalore han sido gestionados en gran medida por las comunidades auto-organizadas, en asocio con entidades gubernamentales. Estas acciones colectivas han tenido un gran éxito a nivel ecológico. La recuperación de los lagos y su reintegración a la vida urbana ha sido un proceso socio-ecológico, en otras palabras: de origen social y colectivo, con efectos y repercusiones sobre los ecosistemas acuáticos y su biodiversidad.

En Polonia, Grochowska et al. (2014) realizaron un estudio en el lago Dlugie, situado al oeste de la ciudad de Olsztyn. Este cuerpo de agua, cuya extensión alcanza las 26.8 hectáreas, sirvió como colector de aguas residuales domésticas desde 1950 hasta mediados de la década de 1970, cuando se tomaron las primeras medidas de protección. A partir de 1987 y hasta el 2000, se realizaron una serie de trabajos de aireación artificial, para mejorar la calidad del agua que se encontraba completamente contaminada. Posteriormente se aplicaron al cuerpo de agua algunos agentes químicos (coagulante de aluminio) con el propósito de inactivar el fósforo que se mantenía presente. Aunque los métodos de restauración aplicados al lago Dlugie fueron exitosos y los atributos estéticos y recreativos del lago han sido recuperados, los resultados de Grochowska et al. evidencian que es muy difícil obtener buena calidad del agua en un lago degradado por la inadecuada actividad humana. 
Los procesos de restauración, rehabilitación o restauración de los lagos contaminados son bastante prolongados. El lago Onondaga en el estado de Nueva York — por ejemplo—, en torno al cual se desarrolló la ciudad de Siracusa, después de un siglo de recibir descargas municipales e industriales continúa siendo el lago más contaminado de Norte América, aunque gracias a los procesos de descontaminación y rehabilitación poco a poco está recuperando su salud y vitalidad. De acuerdo con Kirby \& Ringler (2015), actualmente cuenta con ocho especies de macrófitas y catorce de macroinvertebrados, especies que hacen parte de la cadena alimenticia de peces y aves acuáticas, lo que hace inferir que la salud del ecosistema está mejorando significativamente. De otro lado, pero en el mismo lago, Effler\& Matthews (2008) realizaron estudios con el objetivo de evaluar las implicaciones de los procesos de reducción de la oxidación (redox), puesto que estos investigadores consideran que el objetivo principal de los programas de rehabilitación de los lagos consiste en la recuperación de los niveles de oxígeno disuelto (OD), que se han perdido por efecto de la degradación o la contaminación del agua.

Otro ejemplo que ilustra la lentitud de los procesos de restauración en lagos urbanos, es el seguimiento que Huser et al. (2016) han hecho a un proceso de restauración de cuatro lagos urbanos ( $\mathrm{Ce}$ dar Lake, Lake of the Isles, Lake Calhoun y Lake Harriet) que hacen parte de la cadena de lagos de Minneapolis, en Minnesota, Estados Unidos. En el proceso, que se inició en 1990 y se extendió por más de diez años, se invirtieron 12,3 millones de dólares. El concepto de restauración buscaba la reducción del fósforo total que contenían los lagos en aquella época, y para lograrlo, se realizaron controles para reducir el ingreso de fósforo, y además, se les aplicó alumbre (sulfato de aluminio) en distintas proporciones para reducir a la mitad el contenido de fósforo. Los resultados del proyecto son muy variados. Por ejemplo, la carga externa de fósforo se logró reducir aproximadamente en un $1 \%$ en el Lake of the Isles, y en un $49 \%$ en Cedar Lake. El tratamiento con alumbre fue efectivo hasta 2013 en Cedar Lake, mientras que en Calhoun Lake continúa siendo eficaz. Cabe subrayar que luego de 25 años de iniciado el proceso, solamente uno de los cuatro lagos continua manteniendo los niveles de calidad del agua buscados inicialmente. Este proceso, que ha sido muy bien monitoreado y referenciado por distintos investigadores, permite vislumbrar la difícil tarea que se emprende cuando se pretende rehabilitar o restaurar un ecosistema lacustre en áreas urbanas.

La rehabilitación de los lagos urbanos exige una gran inversión de tiempo, esfuerzo y recursos económicos, y por ser una labor compleja y delicada, en muchos casos cuando se cree logrado el objetivo, el material contaminante continúa presente. Tal es el caso del lago Ciuperca, en la ciudad de Tulcea, Rumania — situado en la zona de inundación del Danubio—, que tras recibir descargas contaminantes desde 1830, fue recuperado y reintegrado a la vida urbana a partir de 2011. Pero aunque el lago se usa actualmente como área recreativa y zona de baño para la ciudadanía, las investigaciones de Török, de 2013, evidencian la presencia de cianobacterias que representan alto riesgo para la salud de los seres humanos.

Por último cabe decir que dentro de los procesos de restauración o rehabilitación de los lagos urbanos, cumple un papel preponderante la medición de la clorofila-a. Es un paso inicial de diagnóstico que permite establecer, por ejemplo, las zonas en las que se presenta la mayor concentración de nutrientes, para ejecutar acciones que reduzcan dicho exceso (Dunalska et al., 2015). Este indicador también permite cuantificar la biomasa conformada por el fitoplancton, con el fin de tomar medidas en cuanto a la reducción de la entrada de fósforo a los ecosistemas, y así, minimizar una de las causas de eutrofización y deterioro. 


\section{CONCLUSIONES}

Los lagos han acompañado al ser humano en la construcción de su hábitat a lo largo de la historia. Su presencia en las ciudades es fuente inagotable de beneficio para el paisaje urbano, la salud física y mental de los ciudadanos, la conservación de la biodiversidad, la sostenibilidad económica, el turismo y la regulación del clima urbano, entre otras cosas. Por tanto, es prioritario que los planificadores y diseñadores urbanos valoren y rescaten estos importantes elementos del urbanismo azul, ese nuevo concepto de la planificación urbana y territorial que estudia y maneja los cuerpos de agua urbanos de manera independiente, sin supeditarlos a otras estructuras urbanas - como la infraestructura verde, por ejemplo-, sino que los plantea autónomos, realzando su importancia dada por su gran potencial estético, cultural, psicológico, educativo, espiritual, ecológico, ambiental, biológico y geoquímico, para beneficio de las urbes.

En cientos de ciudades los lagos están actualmente contaminados, mientras que en otras tantas ocurre algo muy distinto: no hay lagos. De manera que es labor de los planificadores y diseñadores urbanos rehabilitar o restaurar los lagos urbanos allí donde estén deteriorados, y —siguiendo el ejemplo de Le Corbusier en Chandigarh- proponer la construcción de lagos artificiales en las ciudades que carecen de ellos, como parte de las estrategias de planificación urbana que buscan ciudades sostenibles. Por último cabe subrayar que es importante vincular, a los procesos de recuperación de los lagos deteriorados y a la creación de nuevos lagos artificiales, tanto a las comunidades como a los ecosistemas naturales, de manera que, desde un enfoque socio-ecológico, se generen y fortalezcan ciudades más sustentables y más resilientes frente a las amenazas del cambio climático.

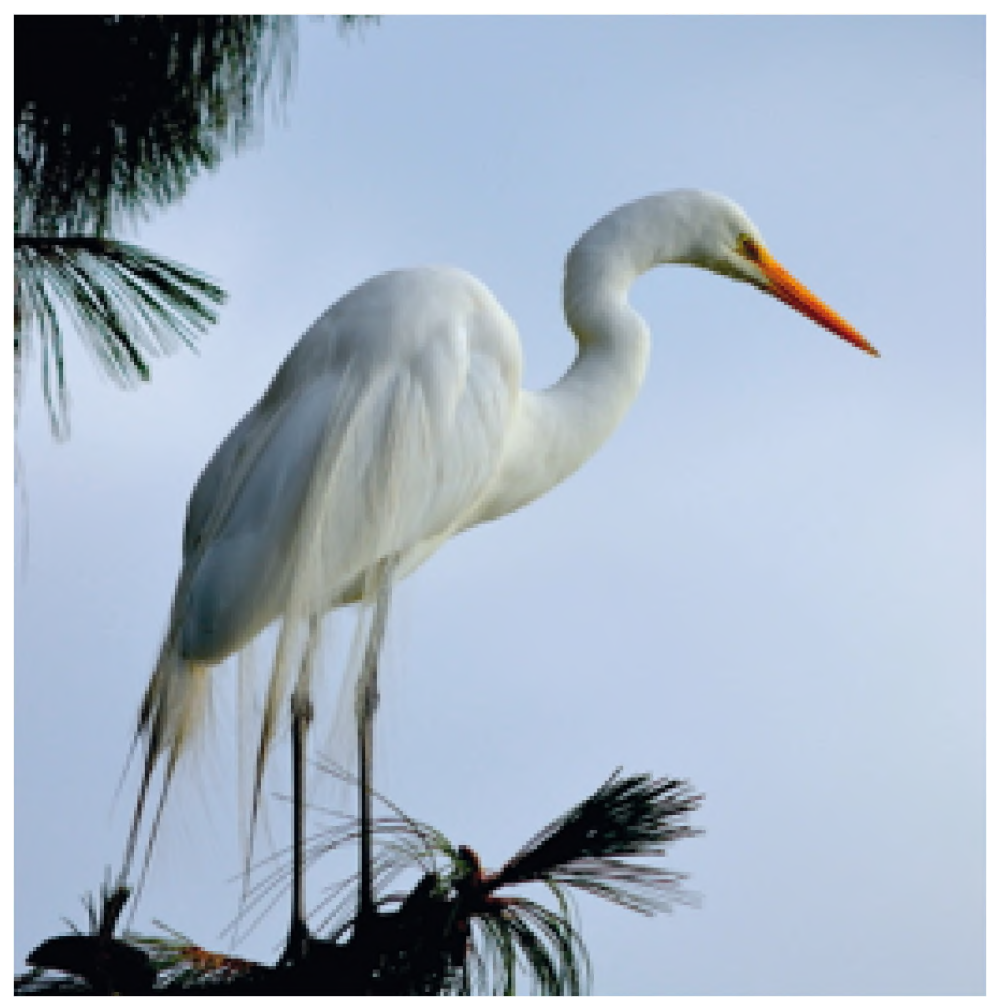

Figura 4. Garza blanca (Casmerodius albus). Parque El Lago, Bogotá. Fuente: Elaboración propia. 


\section{REFERENCIAS}

Ahmed, W., Yusuf, R., Hasan, I., Goonetilleke, A. \& Gardner, T. (2010). Quantitative PCR assay of sewage-associated Bacteroides markers to assess sewage pollution in an urban lake in Dhaka, Bangladesh. Canadian Journal of Microbiology, 56(10), 838-845. doi: 10.1139/w10-070

Almanza-Marroquín, V., Figueroa, R., Parra, O., Fernández, X., Baeza, C., Yañez, J. \& Urrutia, R. (2016). Bases limnológicas para la gestión de los lagos urbanos de Concepción, Chile. Latin American Journal of Aquatic Research, 44(2), 313-326. doi: 10.3856/vol44-issue2-fulltext-12

American Public Health Association-APHA (2005). Standard method for examination of water and wastewater, 21st edn. Washington: APHA, AWWA, WPCF.

Arzate-Cárdenas, M. A., Olvera-Ramírez, R. \& Martínez-Jerónimo, F. (2010). Microcystis toxigenic strains in urban lakes: a case of study in Mexico City. Ecotoxicology, 19(6), 1157-1165. doi: 10.1007/s10646-010-0499-7

Azizuddin, A. D., Ali, N. A. M., Tay, K. S., Abas, M. R. B. \& Simoneit, B. R. (2014). Characterization and sources of extractable organic matter from sediment cores of an urban lake (Tasik Perdana), Kuala Lumpur, Malaysia. Environmental Earth Sciences, 71(10), 4363-4377. doi: 10.1007/ s12665-013-2830-0

Bacchin, T.K., Ashley, R., Sijmons, D., Zevenbergen, C. \& Timmeren, A. (2014). Green-Blue Multifunctional Infrastructure: An Urban Landscape System Design New Approach. 13th International Conference on Urban Drainage, Sarawak, Malaysia, 7-12 September 2014.

Beatley, T. (2014). Blue urbanism: exploring connections between cities and oceans. Washington, Covelo, London: Island Press.

Begon, M., Harper, J. L. \& Townsend, C. R. (2006). Ecology: Individuals, Populations and Communities. Oxford: Blackwell science.

Benevolo, L. (1984). Orígenes del urbanismo moderno. Madrid: Celeste Ediciones.

Bonansea, M., Ledesma, C., Rodríguez, C. \& Sánchez Delgado, A. R. (2012). Concentración de clorofila-a y límite de zona fótica en el embalse Río Tercero (Argentina) utilizando imágenes de satélite CBERS-2B. Revista Ambiente \& Agua, 7(3), 61-71. Recuperado de http://www.scielo. $\mathrm{br} / \mathrm{pdf} / \mathrm{ambiagua/v7n3/v7n3a06.pdf}$

Brown, R.R. \& Clarke, J. (2007). Transition to Water Sensitive Urban Design: the story of Melbourne, Australia. Melbourne: Facility for Advancing Water Biofiltration/ Monash University.

Calderón Guerrero, C.; Saiz De Omeñaca González, J. A. \& Günthardt-Goerg, M. S. (2009). Contribución del arbolado urbano y periurbano del municipio de Madrid en la mejora de la calidad del aire y sumidero de contaminantes atmosféricos como beneficio para la sociedad. Madrid: Sociedad Española de Ciencias Forestales. 
LÍNEA DE INVESTIGACIÓN 1: ARQUITECTURA, CIUDAD, MEDIO AMBIENTE. 2. BIOTECNOLOGÍA CON MICROALGAS

Carvajal-Escobar, Y. (2011). Inundaciones en Colombia. ¿Estamos preparados para enfrentar la variabilidad y el cambio climático? Revista Memorias, Vol. 9, № 16: 105-119. Recuperado de http://revistas.ucc.edu.co/index.php/me/article/viewFile/140/141

Cary, M., \& Scullard, H. H. (1975). "The Roman Empire under Augustus". In A History of Rome (pp. 331-350). London: Palgrave Macmillan.

Chaudhry, P., Bhargava, R., Sharma, M. P. \& Tewari, V. P. (2013). Conserving urban lakes for tourism and recreation in developing countries: a case from Chandigarh, India. International Journal of Leisure and Tourism Marketing, 3(3), 267-281. doi: http://dx.doi.org/10.1504//JLTM.2013.052634

Cherrared, M., Chocat, B. \& Benzerra, A. (2007). Problématique et faisabilité du développement durable en matière d'assainissement urbain en Algérie. NOVATECH 2007.

Conrad, H. P., Wannous, J. H. \& Pakzad, P. (2015). Thermal impact of blue infrastructure: Casestudy Cheonggyecheon, Seoul (Korea). ICUC9 - 9th International Conference on Urban Climate jointly with 12th Symposium on the Urban Environment.

Danielopol, D. L. (1976). The distribution of the fauna in the interstitial habitats of riverine sediments of the Danube and the Piesting (Austria). International Journal of Speleology, 8, 23-51. Recuperado de http://scholarcommons.usf.edu/cgi/viewcontent. cgi?article=1511\&context=ijs

Deak, J., \& Bucht, E. (2011). Planning for climate change: the role of indigenous blue infrastructure, with a case study in Sweden. Town Planning Review, 82(6), 669-685. doi: 10.2307/41300367

Domingos, P., Gômara, G. A., Freitas Sampaio, G., Soares, M. F., \& Lopes Soares, F. F. (2012). Eventos de mortandade de peixes associados à florações fitoplanctônicas na Lagoa Rodrigo de Freitas: Programa de 10 anos de monitoramento. Oecologia Australis, 16(3), 441-466. doi: http://dx.doi.org/10.4257/oeco.2012.1603.09

Dunalska, J. A., Grochowska, J., Wiśniewski, G. \& Napiórkowska-Krzebietke, A. (2015). Can we restore badly degraded urban lakes? Ecological Engineering, 82, 432-441. doi:10.1016/j.ecoleng.2015.05.037

Effler, S. W., \& Matthews, D. A. (2008). Implications of redox processes for the rehabilitation of an urban lake, Onondaga Lake, New York. Lake and Reservoir Management, 24(2), 122-138. doi: $10.1080 / 07438140809354056$

Elías-Fernández, G., Navarrete-Salgado, N. A., Fernández-Guzmán, J. L. \& Contreras-Rivero, G. (2006). Crecimiento, abundancia y biomasa de Poecilia reticulata en el lago urbano del parque Tezozomoc de la Ciudad de México. Revista Chapingo. Serie ciencias forestales y del ambiente, 12(2), 155-159. Recuperado de http://www.redalyc. org/articulo.oa?id=62912210

Espinosa-Castillo, M. (2008). Procesos y actores en la conformación del suelo urbano en el ex lago de Texcoco. Economía, Sociedad y Territorio, 8(7), 769-798. Recuperado de http://www. redalyc. org/articulo. $0 a ?$ id $=11182709$ 
Foley, R., \& Kistemann, T. (2015). Blue space geographies: Enabling health in place. Health \& Place, 35, 157-165. doi: 10.1016/j.healthplace.2015.07.003

Galán, E., Bloundi, K., González, I. \& Duplay, J. (2009). Evaluación de la contaminación por elementos traza en sedimentos de la Laguna de Nador (Marruecos). Revista de la Sociedad Española de Mineralogía, 11, 87-88. Recuperado de http://www.ehu.eus/sem/macla_pdf/macla11/ Macla11_87.pdf

Gandy, M. (2004). Rethinking urban metabolism: water, space and the modern city. City, 8(3), 363379. doi: $10.1080 / 1360481042000313509$

González Moreno, S., Perales Vela, H. \& Salcedo Álvarez, M. O. (2008). La fluorescencia de la clorofila a como herramienta en la investigación de efectos tóxicos en el aparato fotosintético de plantas y algas. Revista de Educación Bioquímica, 27(4), 119-129. Recuperado de http://www. redalyc.org/pdf/490/49011464003.pdf

Göransson, S. (2013). En ny mötesplats i Lövholmen, Stockholm. Uppsala: Sveriges lantbruksuniversitet. Recuperado de http://stud.epsilon.slu.se/5636/11/goransson_s_130617.pdf

Grochowska, J., Brzozowska, R. \& Parszuto, K. (2014). The influence of different recultivation techniques on primary production processes in a degraded urban lake. Oceanological and Hydrological Studies, 43(3), 211-218. doi: 10.2478/s13545-014-0135-x

Gunkel, G. (2003). Limnología de un lago tropical de alta montaña, en Ecuador: Características de los sedimentos y tasa de sedimentación. Revista de biologia tropical, 51(2), 381-390. Recuperado de http://revistas.ucr.ac.cr/index.php/rbt/article/view/15731/15083

Guo, J. Y., Wu, F. C., Liao, H. Q., Zhao, X. L., Li, W., Wang, J., Wang, L-F. \& Giesy, J. P. (2013). Sedimentary record of polycyclic aromatic hydrocarbons and DDTs in Dianchi Lake, an urban lake in Southwest China. Environmental Science and Pollution Research, 20(8), 5471-5480. doi: $10.1007 / \mathrm{s} 11356-013-1562-8$

Haase, D. (2015). Reflections about blue ecosystem services in cities. Sustainability of Water Quality and Ecology, 5, 77-83. doi:10.1016/j.swaqe.2015.02.003

Hassall, C. (2014). The ecology of urban ponds. Wiley Interdisciplinary Reviews: Water, 1(2), 187206. doi: 10.1002/wat2.1014

Heikkila, E. \& Huang, M. (2014). Adaptation to Flooding in Urban Areas: An Economic Primer. Public Works Management \& Policy, 19 (1), 11-36. doi: 10.1177/1087724X13506559

Helal Ouriachen, E. H. (2011). Continuidad y decadencia: dos constantes compatibles en el devenir urbano del Mediterráneo y del Atlántico durante la Tardo Antigüedad. Revista de Claseshistoria, 4, 1-20. Recuperado de http://www.claseshistoria.com/revista/2011/articulos/helal-ciudadantiguedad.html 
LÍNEA DE INVESTIGACIÓN 1: ARQUITECTURA, CIUDAD, MEDIO AMBIENTE. 2. BIOTECNOLOGÍA CON MICROALGAS

Hilker, N., Badoux, A. \& Hegg, C. (2009). The Swiss flood and landslide damage database 1972-2007. Natural Hazards Earth System Sciences, 9, 913-925. Recuperado de http://www.wsl.ch/fe/gebirgshydrologie/HEX/projekte/schadendatenbank/download/nhess-9-913-2009_lq.pdf

Huser, B. J., Futter, M., Lee, J. T. \& Perniel, M. (2016). In-lake measures for phosphorus control: The most feasible and cost-effective solution for long-term management of water quality in urban lakes. Water Research, 97, 142-152. doi: 10.1016/j.watres.2015.07.036

Islam, M., Kitazawa, D., Runfola, D. M. \& Giner, N. M. (2012). Urban lakes in a developing nation: Drivers, states and impacts of water quality and quantity in Dhaka, Bangladesh. Lakes \& Reservoirs: Research \& Management, 17(4), 253-263. doi: 10.1111//re.12010

Jakabfi, G. (2016). Blue Landscape Urbanism in Budapest, Hungary. The Role of WSUD in Community Building. Thesis, Estonian University of Life Sciences.

Kalaji, H. M., Sytar, O., Brestic, M., Samborska, I. A., Cetner, M. D. \& Carpentier, C. (2016). Risk assessment of urban lake water quality based on in-situ cyanobacterial and total chlorophyll-a monitoring. Polish Journal of Environmental Studies, 25(2), 655-661. doi: 10.15244/pjoes/60895

Kaushal, S. S., McDowell, W. H., Wollheim, W. M., Newcomer, T. A., Mayer, P. M., Belt, K. T. \& Pennino, M. J. (2015). Urban evolution; the role of water. Water, 7, 4063-4087. doi:10.3390/ w7084063

Kirby, L. J. \& Ringler, N. H. (2015). Associations of Epiphytic Macroinvertebrates within Four Assemblages of Submerged Aquatic Vegetation in a Recovering Urban Lake. Northeastern Naturalist, 2(4), 672-689. doi: http://dx.doi.org/10.1656/045.022.0404

Lederer, J. \& Kral, U. (2015). Theodor Weyl: A pioneer of urban metabolism studies. Journal of Industrial Ecology, 19(5), 695-702. http://dx.doi.org/10.1111/jiec. 12320

Liu, Y. (2014). Dynamic evaluation on ecosystem service values of urban rivers and lakes: A case study of Nanchang City, China. Aquatic Ecosystem Health \& Management, 17(2), 161-170. doi: 10.1080/14634988.2014.907223

Lundy, L. \& Wade, R. (2011). Integrating sciences to sustain urban ecosystem services. Progress in Physical Geography, 35(5), 653-669. doi: 10.1177/0309133311422464

Malakpour, S., Kerachian, R. \& Nikoo, M. R. (2016). Developing water quality management policies for the Chitgar urban lake: application of fuzzy social choice and evidential reasoning methods. Environmental Earth Sciences, 75, 404. doi:10.1007/s12665-015-5065-4

Manly, R. \& Owen, W. (1970). The occurrence of some heavy metals in populations of the freshwater mussel Anodonta anatina (L.) from the river Thames. Environmental Pollution, 12(2), 139-154. doi:10.1016/0013-9327(77)90106-9

Margalef, R. (1983). Ecología. Barcelona: Omega. 
McCleery, R. A., Moorman, C. E. \& Peterson, M. N. (2014). Urban Wildife Conservation. Theory and Practice. New York/London: Springer.

Moreno Franco, D. P., Quintero Manzano, J. \& López Cuevas, A. (2010). Métodos para identificar, diagnosticar y evaluar el grado de eutrofia. Contactos, 78, 25-33. Recuperado de http://www. izt.uam.mx/newpage/contactos/anterior/n78ne/eutrofia2.pdf

Moreno Navarro, I. M. (2002). Microcistinas. Presencia, determinación y estudios toxicológicos. Tesis, Universidad de Sevilla.

Moreta Pozo, J. C. (2008). La eutrofización de los lagos y sus consecuencias. Tesis, Universidad Técnica del Norte, Ibarra, Ecuador.

Morris, A. E. J. (1984). Historia de la forma urbana: desde sus orígenes hasta la Revolución Industrial. Madrid: Editorial Gustavo Gili.

Nabout, J. C. \& Nogueira, I. S. (2011). Variação temporal da comunidade fitoplanctônica em lagos urbanos eutróficos. Acta Scientiarum. Biological Sciences, 33(4), 383-391. doi: 10.4025/actascibiolsci.v33i4.5955

Nagendra, H. \& Ostrom, E. (2014). Applying the social-ecological system framework to the diagnosis of urban lake commons in Bangalore, India. Ecology and Society, 19(2), 67-86. doi.org/10.5751/ ES-06582-190267

Naselli-Flores, L. (2008). Urban Lakes: Ecosystems at Risk, Worthy of the Best Care. Sengupta, M. and Dalwani, R. (Editors). (2008) Proceedings of Taal 2007: The 12th World Lake Conference: 1333-1337.

Nelson, V., Moddemeyer, S. and Schwartz, P. (2007). The Baltimore Charter for Sustainable Water Systems. http://sustainablewaterforum.org/baltimore.html

Newton, R. J., Bootsma, M. J., Morrison, H. G., Sogin, M. L. \& McLellan, S. L. (2013). A microbial signature approach to identify fecal pollution in the waters off an urbanized coast of Lake Michigan. Microbial Ecology, 65(4), 1011-1023. doi: 10.1007/s00248-013-0200-9

Newman, D.J., Perault, D.R. \& Shahady, T.D. (2006). Watershed development and sediment accumulation in a small urban lake. Lake and Reservoir Management, 22(4):303-307. doi: $10.1080 / 07438140609354364$

Noble, A. \& Hassall, C. (2015). Poor ecological quality of urban ponds in northern England: causes and consequences. Urban Ecosystems, 18(2), 649-662. doi: 10.1007/s11252-014-0422-8

Nutsford, D., Pearson, A. L., Kingham, S. \& Reitsma, F. (2016). Residential exposure to visible blue space (but not green space) associated with lower psychological distress in a capital city. Health \& Place 39, 70-78. doi: 10.1016/j. healthplace.2016.03.002 
LÍNEA DE INVESTIGACIÓN 1: ARQUITECTURA, CIUDAD, MEDIO AMBIENTE. 2. BIOTECNOLOGÍA CON MICROALGAS

Paerl, H. W. \& Otten, T. G. (2013). Harmful cyanobacterial blooms: causes, consequences, and controls. Microbial Ecology, 65(4), 995-1010. doi: 10.1007/s00248-012-0159-y

Patil, K. G., Shende, V. A. \& Janbandhu, K. S. (2015). Human impacton urban lake Futala-Telangkhedi: a case study. International Journal of Researches in Biosciences, Agriculture and Technology, 2(3), 60-62.

Pineda-Mendoza, R. M., Olvera-Ramírez, R., \& Martínez-Jerónimo, F. (2012). Microcystins produced by filamentous cyanobacteria in urban lakes. A case study in Mexico City Microcistinas producidas por cianobacterias filamentosas en lagos urbanos. Un estudio de caso en la Ciudad de México. Hidrobiológica, 22(3), 290-298. Recuperado de http://www.scielo.org.mx/pdf/hbio/ v22n3/v22n3a10.pdf

Pizarro, J., Vergara, P. M., Cerda, S. \& Briones, D. (2016). Cooling and eutrophication of southern Chilean lakes. Science of the Total Environment, 541, 683-691. doi: 10.1016/j.scitotenv.2015.09.105

Peterson, T. C., Heim Jr, R. R., Hirsch, R., Kaiser, D. P., Brooks, H., Diffenbaugh, N. S., ... and Katz, R. W. (2013). Monitoring and understanding changes in heat waves, cold waves, floods, and droughts in the United States: state of knowledge. Bulletin of the American Meteorological Society, 94(6), 821-834. http://dx.doi.org/10.1175/BAMS-D-12-00066.1

Quirós, R. (2004). Cianobacterias en lagos y embalses de Argentina: década del 80 . Buenos Aires: Universidad de Buenos Aires.

Rajashekara, S. \& Venkatesha, M. G. (2014). Eco-spatial and Temporal Variation in Waterbirds Composition and their relationship with Habitat Characteristics of Urban Lakes of Bengaluru city, India. International Journal, 2(7), 60-80.

Ranger, N.; Hallegatte, S.; Bhattacharya, S.; Bachu, M.; Priya, S.; Dhore, K.; Rafique, F.; Mathur, P.; Naville, N.; Henriet, F.; Herweijer, C.; Pohit, S. \& Corfee-Morlot, J. (2011). An assessment of the potential impact of climate change on flood risk in Mumbai. Climatic Change, $N^{\circ} 104: 139-167$. doi: $10.1007 / \mathrm{s} 10584-010-9979-2$

Ratheesh Kumar, R., Purushothaman, C. S., Sreekanth, G. B., Manju Lekshmi, N., Renjith, V., Sandeep, K. P. \& Pandey, P. (2015). State of Water Quality of Two Tropical Urban Lakes Located at Mumbai Megacity. International Journal of Science and Research, 4(5), 1991-1998. Recuperado de http://www.ijsr.net/archive/v4i5/SUB154650.pdf

Raymond, C. M., Gottwald, S., Kuoppa, J. \& Kyttä, M. (2016). Integrating multiple elements of environmental justice into urban blue space planning using public participation geographic information systems. Landscape and Urban Planning, 153, 198-208. doi:10.1016/j.landurbplan.2016.05.005

Redaud, J.; Noilhan, J.; Gillet, M.; Huc, M. \& Begne, G. (2002). Changement climatique et impact sur le regime des eaux en France. Toulouse: Ministère de l'Ecologie et du développement Durable. 
Remolina, F. (2011). Figuras municipales de conservación ambiental en Colombia: ¿áreas protegidas, redes ecológicas o infraestructuras verdes? Revista Nodo, 11(6), 65-76. Recuperado de https://dialnet.unirioja.es/servlet/articulo?codigo $=3983371$

Rodrigues, A. E. M. (2012). Lagoa Rodrigo de Freitas/RJ: história de uma ocupação desordenada. Oecologia Australis, 16(3), 339-352. http://dx.doi.org/10.4257/oeco.2012.1603.03

Rodríguez, E., Ruíz, M. \& Vertíz Pérez, L. A. (1997). Procesos de eutroficación en siete lagunas urbanas de Villahermosa, Tabasco, México. Congreso Regional de AIDIS para Norteamérica y El Caribe, San Juan, 8-12 jun. 1997. Recuperado de http://www.bvsde.paho.org/bvsaidis/ puertorico/xli.pdf

Santiago Lastra, J. A., López Carmona, M. \& López Mendoza, S. (2008). Tendencias del cambio climático global y los eventos extremos asociados. Ra Ximhai. Revista de Sociedad, Cultura y Desarrollo Sustentable, 4 (3), 625-633. Recuperado de http://www.redalyc.org/articulo. oa?id=46140307

Singh, S. K., Singh, P., \& Gautam, S. K. (2016). Appraisal of urban lake water quality through numerical index, multivariate statistics and earth observation data sets. International Journal of Environmental Science and Technology, 13(2), 445-456. doi: 10.1007/s13762-015-0850-x

Spears, B. M., Carvalho, L., Dudley, B. \& May, L. (2013). Variation in chlorophyll a to total phosphorus ratio across 94 UK and Irish lakes: Implications for lake management. Journal of Environmental Management, 115, 287-294. doi: 10.1016/j.jenvman.2012.10.011

Strümpfer, D. J. W. (1990). Salutogenesis: A new paradigm. South African Journal of Psychology, 20(4), 265-276. doi: 10.1177/008124639002000406

Takano, T., Nakamura, K. \& Watanabe, M. (2002). Urban residential environments and senior citizens' longevity in megacity areas: the importance of walkable green spaces. Journal of epidemiology and community health, 56(12), 913-918. doi: 10.1136/jech.56.12.913

Tailor, M. \& Mankodi P. (2013). Comparative study of two Urban Ponds of Vadodara city with special reference to their chemical parameters. Research Journal of Animal, Veterinary and Fishery Sciences, 1(10), 10-15. Recuperado de http://www.isca.in/AVFS/Archive/v1/i10/2.ISCA-RJAVFS-2013-058.pdf

Tanaka, A., Takano, T., Nakamura, K. \& Takeuchi, S. (1996). Health levels influenced by urban residential conditions in a megacity-Tokyo. Urban Studies, 33(6), 879-894. doi: 10.1080/00420989650011645

Thieken, A. H., Bessel, T., Kienzler, S., Kreibich, H., Müller, M., Pisi, S. \& Schröter, K. (2016). The flood of June 2013 in Germany: how much do we know about its impacts? Natural Hazards and Earth System Sciences (NHESS). doi:10.5194/nhess-2015-324

Török, L. (2013). Hazard risk and alert level in assessment of a rehabilitated urban lake. Scientific Annals of the Danube Delta Institute, 19, 111-116. doi:10.7427/DDI.19.15 
LÍNEA DE INVESTIGACIÓN 1: ARQUITECTURA, CIUDAD, MEDIO AMBIENTE. 2. BIOTECNOLOGÍA CON MICROALGAS

Vera-Franco, M., Hernández-Victoria, P., Alcocer, J., Ardiles-Gloria, V. \& Oseguera, L. (2015). "Concentración y distribución vertical de la clorofila-a fitoplanctónica en los lagos de Montebello, Chiapas". En: Alcocer, J., M. Merino-Ibarra, E. Escobar-Briones. (Editores). 2015. Tendencias de investigación en Limnologia tropical: Perspectivas universitarias en Latinoamérica. México D. F.: Asociación Mexicana de Limnología / Instituto de Ciencias del Mar y Limnología, UNAM/ Consejo Nacional de Ciencia y Tecnología.

Voigt, A., Kabisch, N., Wurster, D., Haase, D. \& Breuste, J. (2014). Structural Diversity: A Multidimensional Approach to Assess Recreational Services in Urban Parks. AMBIO, A Journal of the Human Environment, 43, 480-491. doi: 10.1007/s13280-014-0508-9

Völker, S. \& Kistemann, T. (2015). Developing the urban blue: Comparative health responses to blue and green urban open spaces in Germany. Health \& place, 35, 196-205. doi: 10.1016/j. healthplace.2014.10.015

Völker, S., Baumeister, H., Classen, T., Hornberg, C. \& Kistemann, T. (2013). Evidence for the temperature-mitigating capacity of urban blue space-A health geographic perspective. Erdkunde, 67(4), 355-371. doi: 10.3112/erdkunde.2013.04.05

Von Malotki, A. (2015). Understanding and managing urban aquatic and terrest systems. Blue Infrastructure. London: King's College.

Waajen, G. W., Faassen, E. J. \& Lürling, M. (2014). Eutrophic urban ponds suffer from cyanobacterial blooms: Dutch examples. Environmental Science and Pollution Research, 21(16), 99839994. doi: 10.1007/s11356-014-2948-y

Wade, S., Faye, S., Dieng, M., Kaba, M. \& Kane, N. R. (2009). Télédétection des catastrophes d'inondation urbanie: le cas de la región de Dakar (Sénégal). Journées d'Animation Scientifique (JAS09) de I'AUF Alger, Novembre 2009. Recuperado de http://www.reseautd.cict.fr/alger/ Articles_PDF_apres_correction_et_evaluation/A53_Souley_Wade_JAS09.pdf

Wagner, I., Krauze, K. \& Zalewski, M. (2013). Blue aspects of green infrastructure. Sustainable Development Applications, 4, 145-155. Recuperado de http://sendzimir.org.pl/sites/default/files/ mag4en/11_Blue\%20aspects\%20of\%20green\%20infrastructure.pdf

Wainger, L., Yu, H., Gazenski, K. \& Boynton, W. (2016). The relative influence of local and regional environmental drivers of algal biomass (chlorophyll-a) varies by estuarine location. Estuarine, Coastal and Shelf Science, 178, 65-76. doi:10.1016/j.ecss.2016.05.024

Wilby, R. \& Keenan, R. (2012). Adapting to flood risk under climate change. Progress in Physical Geography, 36 (3): 1-31. doi: 10.1177/0309133312438908

Williams, S. C., Simpson, H. J., Olsen, C. R. \& Bopp, R. F. (1978). Sources of heavy metals in sediments of the Hudson River Estuary. Marine Chemistry, 6(3), 195-213. doi:10.1016/03044203(78)90030-0 
Wu, Q., Xia, X., Li, X. \& Mou, X. (2014). Impacts of meteorological variations on urban lake water quality: a sensitivity analysis for 12 urban lakes with different trophic states. Aquatic sciences, 76(3), 339-351. doi:10.1007/s00027-014-0339-6

Zeng, Y. (2010). A risk assessment on the alga bloom in city - A case of the "six seas" urban lakes in Beijing. Procedia Environmental Sciences, 2(5), 1501-1509. doi:10.1016/j.proenv.2010.10.163

Zhang, Z., Cui, B. \& Fan, X. (2012). Removal mechanisms of heavy metal pollution from urban runoff in wetlands. Frontiers of Earth Science, 6(4), 433-444. doi:10.1007/s11707-012-0301-7

Zhang, Z., Tan, S. \& Tang, W. (2015). A GIS-based spatial analysis of housing price and road density in proximity to urban lakes in Wuhan City, China. Chinese Geographical Science, 25(6), 775790. doi:10.1007/s11769-015-0788-4. 